\title{
Use of automatic computerised pump to maintain constant intragastric $\mathrm{pH}$
}

\author{
A Hannan, I Chesner, H S Merki, S Mann, R P Walt
}

\begin{abstract}
We used continuous variable rate infusions of famotidine in eight normal volunteers under fasting conditions to raise intragastric $\mathrm{pH}$ to 5.0. An intragastric glass electrode continuously monitored acidity and this information was automatically computed to regulate an intravenous infusion system (GastroJet). The computer was programmed to aim for $\mathrm{pH}$ 6.0 , increasing and lowering infusion rates accordingly. Two regimens were compared with placebo (10 $\mathrm{mg}$ bolus followed by infusion or infusion of famotidine alone). Volunteers were admitted to an investigation ward and each study was preceded by a standard normal meal. Hydration was maintained with intravenous fluids. During placebo treatment the median $\mathrm{pH}$ was 1.5 and the $\mathrm{pH}$ was $<5.0$ for $98 \%$ of the time. All volunteers responded to famotidine but dosage requirements varied (range $41 \mathrm{mg}$ to $126 \mathrm{mg}$ ). The median $\mathrm{pH}$ rose to 6.5 when infusions of famotidine followed boluses and to 6.6 when infusions alone were used - the pH was $<5.0$ for $20 \%$ and $16 \%$ of the time respectively ( $<<0.05$ Wilcoxon compared with placebo). Mean drug use was greater with boluses (98 $\mathrm{mg} v 87 \mathrm{mg} \mathrm{p}=0.03$ : paired Student's $t$ test) and onset was not apparently faster. Blood famotidine concentrations followed infusion rate changes. Famotidine infused by GastroJet maintains a high fasting intragastric $\mathrm{pH}$ and priming boluses are probably unnecessary.
\end{abstract}

Intravenous antisecretory agents are commonly used to limit peptic activity in the stomach by raising the gastric $\mathrm{pH}$. Hitherto, regimens have been empirical and similar for all subjects. It has been shown that continuous infusions of famotidine raises the gastric $\mathrm{pH}$ to 5 or higher in fasted duodenal ulcer patients. ${ }^{1}$ To achieve consistent responses, a higher dose of drug than is needed is infused for some patients. A new computerised infusion pump (GastroJet, MIC, Switzerland) has been developed to circumvent this difficulty. This device registers gastric $\mathrm{pH}$ and adjusts the rate of drug delivery accordingly. One might envisage its use in intensive care units when attempts are made to closely control intragastric $\mathrm{pH}$ over prolonged periods. We have assessed the ability of this pump to infuse famotidine at rates sufficient, firstly, to raise gastric $\mathrm{pH}$ to $5 \cdot 0$ and, secondly, to maintain acidity at this value over 24 hours.

\section{Methods}

The GastroJet consists of a small volume peristaltic pump capable of infusing agents at rates between $1 \mu \mathrm{l} /$ minute and $99 \mu \mathrm{l} /$ minute. There are 11 variable rate settings, which are programmable. Infusion rates during use are increased or decreased automatically in response to $\mathrm{pH}$ measurements fed back from a solid state $\mathrm{pH}$ recorder. The latter records $\mathrm{pH}$ at six second intervals from a $4 \mathrm{~mm}$ combined glass electrode (Ingold M440, Switzerland). The $\mathrm{pH}$ recording system has previously been described and validated. ${ }^{1-5} \mathrm{~A}$ target $\mathrm{pH}$ is programmed and infusion rates are adjusted upwards until this value is reached. Rates are then decreased at 28 minute intervals while $\mathrm{pH}$ remains at or above target, but are increased after four minutes if the $\mathrm{pH}$ falls below target. A mark is recorded in the machines memory every time the rate is increased or decreased. Preliminary studies with the equipment had suggested that a target $\mathrm{pH}$ one unit higher than that actually expected should be programmed in order to limit fluctuations around the target value itself. A full validation study has been published elsewhere. ${ }^{6}$ Thus, a target of 6.0 was chosen for these studies. Famotidine, $40 \mathrm{ml}(4 \mathrm{mg} / \mathrm{ml})$, or placebo (normal saline) was loaded into plastic infusion bags which fit into the machine. The infusion bags were weighed before and after each study day to check on total infusion volumes.

\section{VOLUNTEERS}

Eight healthy students (five men) participated in the study. They had normal biochemical profiles and haematology before entry and none required regular medication of any sort. The mean age was 22 years (range 20-25 years), mean weight was $72 \mathrm{~kg}$ (59-93 kg), and two were smokers. Informed consent was given and the study approved by the Central Birmingham Health Authority ethics committee.

\section{PROCEDURES}

Volunteers attended the investigation unit at 1230 and a standard lunch was supplied (soup and roll, lasagne and ratatouille, chocolate mousse, coffee and mint chocolates: JS Sainsbury). The menu, quantity, and time of lunch were the same on every study day. Cigarette smoking and alcohol were not allowed. Subjects were fasted thereafter throughout the study until completion at $\mathbf{1 6 0 0}$ hours the following day. At 1530 the nasogastric electrode was passed into the stomach (with continuous $\mathrm{pH}$ readings the oesophagogastric junction is easily identified and the tip is advanced $10 \mathrm{~cm}$ from this $\mathrm{pH}$ change), fixed to the face, and connected to the GastroJet. An intravenous cannula was inserted into a forearm vein and connected via a three way tap to the infusion tube of the 
GastroJet. The third arm of the tap was used to infuse 2-3 1 of fluid (normal saline and 5\% dextrose) over the next 24 hours. The GastroJet was programmed to start at 1600 hours and ran uninterrupted until 1600 hours the following day. The volunteers stayed on the investigation ward throughout the study but were free to move about. At the end of the studies cannulae and electrodes were removed. Recalibration at $\mathrm{pH}$ $7 \cdot 0$ and $4 \cdot 0$ was performed to ensure that electrode drift was minimal. The volume of infusate was calculated by weight and compared with that expected from recorded infusion rates.

Each volunteer underwent three separate studies which compared placebo, famotidine plus a $10 \mathrm{mg}$ priming bolus at 1600 hours, and famotidine without a priming bolus. Priming boluses were given by hand injection over one minute. Studies were single blind but randomised and separated by at least five days. Venous blood samples for famotidine assays were collected through an indwelling cannula in the opposite arm to the infusions at hourly intervals for the first eight hours and at one or two hourly intervals after 16 hours (sleep was not interrupted). Famotidine was assayed using high performance liquid chromatography. ${ }^{7}$

\section{ANALYSIS}

The placebo study was done to ensure that the subjects had normal intragastric acidity. Paired comparisons with active treatment by Wilcoxon signed rank tests of the proportion of time that the $\mathrm{pH}$ was above 5 were performed. Active treatments were similarly compared. As a descriptive measure of onset of action of famotidine, repeated Student's $t$ tests were performed for 15 minute medians. Onset of action was taken to be the time when two consecutive quarter hour periods were significantly different from placebo. The total quantity of famotidine infused was also compared between treatments by Student's $t$ test. Famotidine serum values were averaged and are presented over time.

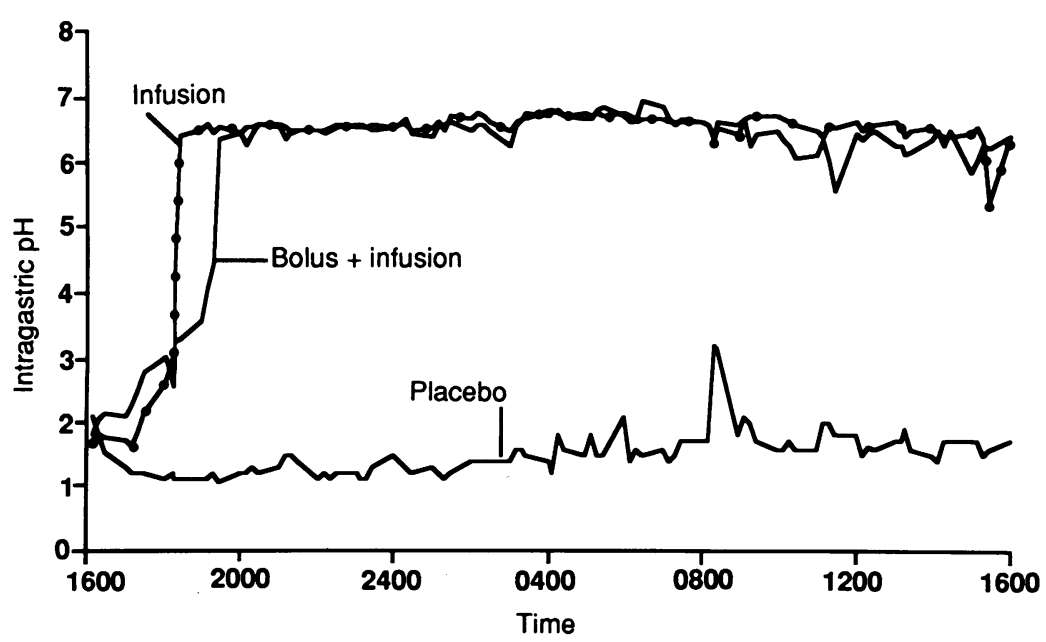

Figure 1: Median intragastric $\mathrm{pH}$ during famotidine and placebo infusions in normal volunteers.

The 15 minute median values have been plotted for placebo $(n=7)$, primed infusions (bolus + infusion), and non-primed infusions. Subjects were fasted throughout.

\section{Results}

The studies were generally well tolerated, although headache was reported by four volunteers during one of the three periods. The symptom was observed during both active and placebo infusions. No other unwanted events were reported or observed. One volunteer refused to undergo a third study (placebo) as he found the procedures involved too unpleasant.

During placebo infusion, the median (range) 24 hour $\mathrm{pH}$ was $1.5(1 \cdot 0-2 \cdot 0)$. Acidity was generally higher during the evening and night than during the day (Fig 1).

The median (range) $\mathrm{pH}$ increased to $6 \cdot 5(6 \cdot 1-$ $6 \cdot 7)$ and $6 \cdot 6(6 \cdot 3-6 \cdot 8)$ with primed famotidine infusion and infusion alone respectively. The mean (SD) $\mathrm{pH}$ was below 5 for $98 \%$ of the time during placebo, $20 \%$ (6) after primed infusions, and $16 \%$ (4) during infusion alone. Individual data are shown in Figure 2. The vast majority of recordings below 5.0 were found during the time before drug action was measurable (Fig 1).

Pump rates were apparently adjusted appropriately during the studies (Fig 3). During placebo, the infusion rate was increased to the fastest and remained at this level throughout in all subjects. During active treatment the $\mathrm{pH}$ profiles were characterised by dips in $\mathrm{pH}$ at times when the infusion rate had been decreased below that needed to maintain the target value. In all cases, the rates were increased rapidly so the amount of time spent with a low $\mathrm{pH}$ was short. The mean (SD) amount of famotidine used was 98 (19) $\mathrm{mg}$ and 87 (26) mg with primed and nonprimed infusions respectively $(p<0.03)$. The calculated total infused was always different from that measured by weighing and on average was $12(3) \%$ less.

Mean plasma famotidine values with either infusion regimen are shown in Figure 4. During the night, the $\mathrm{pH}$ was satisfactorily maintained around the target, with lower infusion rates than those required during the day. Comparison with Figure 3 also shows that the lowest famotidine concentrations were measured when pumping rates were low, as expected.

Assessment of onset of action by our method showed that with a priming bolus mean onset was 45 minutes while infusion alone started at 75 minutes.

\section{Discussion}

This new computerised infusion pump is capable of acting as a gastric secretory block by $\mathrm{pH}$ feedback control. It may be possible for the system to produce consistent intragastric $\mathrm{pH}$ values throughout the $\mathrm{pH}$ scale to 7 but in this study we have only tested its ability to maintain $\mathrm{pH}$ 6. In this study we aimed to raise the $\mathrm{pH}$ to values well above those traditionally assumed to be important for prevention of stress ulceration $(\mathrm{pH} \mathrm{4})$ and in gastrointestinal haemorrhage. ${ }^{89}$ The relative failure of $\mathrm{H}_{2}$ receptor blockade in these clinical circumstances possibly reflects the fact that higher values of $\mathrm{pH}$ are required. We therefore decided to test this system by aiming for a $\mathrm{pH}$ value generally unattainable by other modes of administration.

We anticipated $\mathrm{pH}$ fluctuations around the 


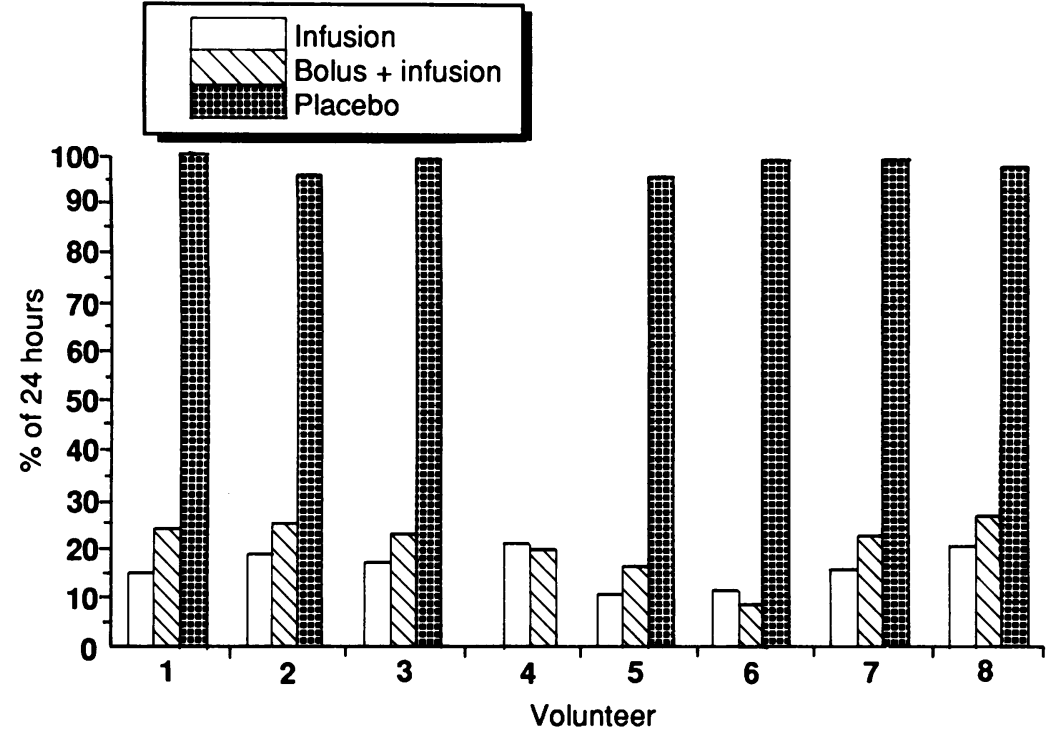

Figure 2: The proportion of time that $\mathrm{pH}$ is less than 5 in normal subjects receiving famotidine or placebo infusions.

Volunteer 4 did not participate in the placebo study.

target value as the machine is programmed to allow the $\mathrm{pH}$ to fall below the target in order to limit drug administration. Preliminary experiments had suggested that the degree of inaccuracy could be substantial, and therefore the target $\mathrm{pH}$ was programmed at 6.0 when the expectation was to maintain a constant $\mathrm{pH}$ of $5 \cdot 0$. In practice the machine achieved the programmed value, thus exceeding our expectations. Clearly, it is not necessary to adjust the programmed target to any value other than that desired.

The pumping rates are accurate to about plus or minus $10 \%$ at rates above $30 \mu \mathrm{l} /$ minute. At lower pump rates accuracy of volume diminishes so we have never used rates below this. To allow smaller volumes than $30 \mu \mathrm{l}$ to be infused each minute, the pump was programmed to have a variable delay time each minute and then pump for a shorter period at a faster rate. The system was checked on the bench before experiments started and this was found to be satisfactory and not associated with increased errors. We weighed the primed infusion bags before and after the studies to check on the accuracy of the pumping mechanism because we knew of its inbuilt error. Our measurements confirmed a difference of around $12 \%$ in the volume infused.

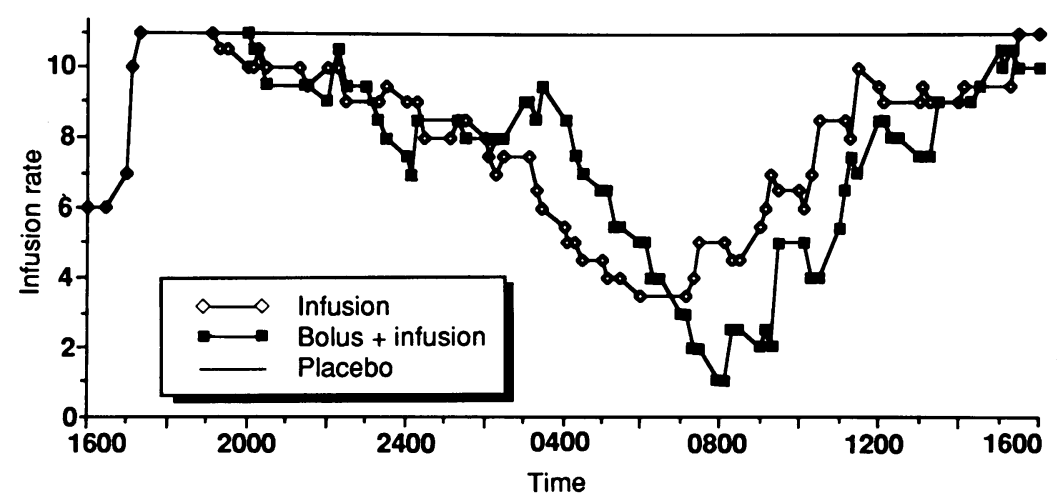

Figure 3: Median pump rate changes during placebo and famotidine infusions.

This graph shows 15 minute median pump rates during all treatments. Individual variation was considerable but the clear trend for rates to be turned down to a nidus in the early morning hours is seen.
This error, however, does not affect the feedback function of the system.

We attempted to assess whether a priming bolus provided important additional antisecretory effects. It seems to give a small additional benefit (Fig 1) in accelerating the onset of action when famotidine is used. This finding depends on the method used to assess the onset of action. We used a statistical technique which should not be subjected to repeated testing. ${ }^{10} \mathrm{We}$ believe our use is justified, however, as no attempt has been made to assess the magnitude of change, simply that change has occurred. An alternative method was also used which defined the onset of action as the time when $80 \%$ or more values in any half hour were greater than or equal to $\mathrm{pH} 4$. This analysis showed that the priming bolus injection delayed the onset of action! This method employs a more arbitrary definition of onset of action and as such is perhaps less powerful. We have concluded that the faster onset with a priming dose is unlikely to be important but accept that it could possibly be disadvantageous. It would be difficult to explain if the latter were true but one might postulate that very high plasma concentrations render receptors less sensitive to further blockade (up regulate). Our conclusion is supported by another study with nizatidine where a priming bolus was not beneficial (Merki HS, personal communication). Over the whole study period, the dose of drug used with primed infusions exceeded that used with infusions alone by approximately the size of the bolus. Despite this, pharmacodynamic effects were not different. Our inability to show that a priming bolus is beneficial may reflect the experimental technique, which measures acidity and takes no account of volume. The initial $\mathrm{pH}$ recordings continue to be low until pre-existing acid is buffered or emptied from the stomach. The priming bolus may have inhibited gastric secretion more quickly, as one would expect, but this fact is obscured by acid already present. Another explanation might be that the bolus injections were not given. This was not the case, even though plasma concentrations one hour later failed to show a difference between bolus or infusion alone (Fig 4). We assume that the peak plasma concentration after a bolus occurs within minutes and that by one hour later it has fallen to values similar to those produced by infusions alone.

This system of drug administration has two potential advantages over existing methods in patients receiving intravenous $\mathrm{H}_{2}$ receptor antagonists. Firstly, the goal of treatment can be seen to be achieved, or not, as the case may be, whereas present treatment is assumed to be pharmacodynamically effective. Secondly, individual dosage titrations are made which ensure that those who require little or no drug get little and those who require more get the right amount. In these studies there was considerable variation in dosage requirement to achieve the same end. It has been suggested that continuous use of $\mathrm{H}_{2}$ blockers is a cause of infection in the intensive treatment unit ${ }^{11-14}$ through continuous gastric hypoacidity. This device has the ability to switch itself off for given preprogrammed periods and allow gastric $\mathrm{pH}$ to fall to values that 


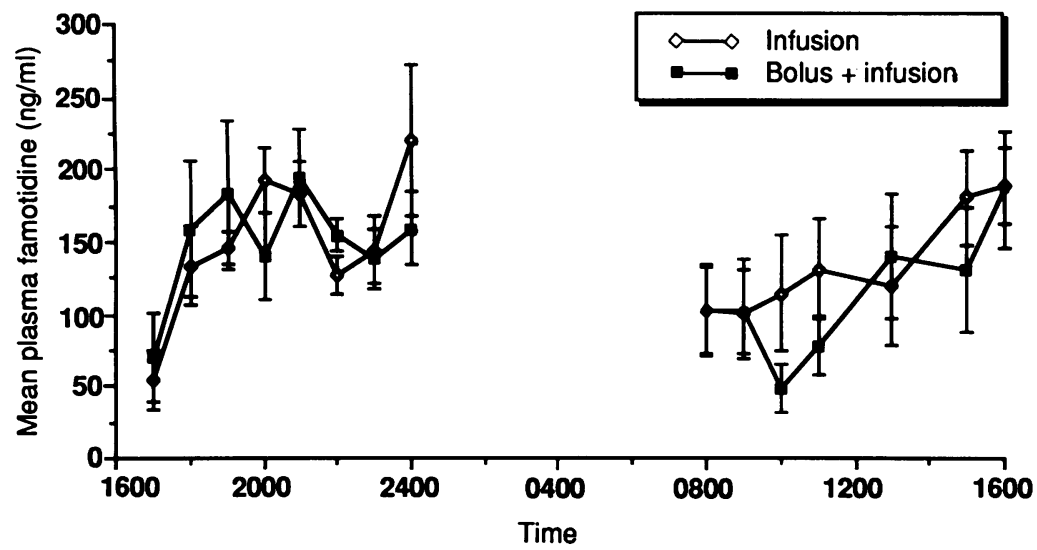

Figure 4: Mean plasma famotidine concentrations during primed and unprimed infusions.

The graphs are not continuous as sampling did not continue through the night. SDs are shown as verticals from the mean. patients who are particularly resistant to a given treatment. It may also be used to study the gastric secretory controlling mechanisms in response to different physiological stimuli. In clinical practice the use of this system in the intensive care unit and in gastrointestinal bleeding deserves assessment.

We gratefully acknowledge a donation from Merck Sharp and We gratefully acknowledge a donation from Merck Sharp and
Dohme (UK). Dr John Kelly is thanked for performing the famotidine assays.

1 Merki HS, Witzel L, Kaufmann D, et al. Continuous intravenous infusions of famotidine maintain high intragastric $\mathrm{pH}$ in duodenal ulcer. Gut 1988; 29: 453-7.

2 Merki HS, Witzel L, Walt RP, et al. Day to day variation of 24hour intragastric acidity. Gastroenterology 1988; 94: 887-91.

3 Fimmel CJ, Etienne A, Cillufo T, et al. Longterm ambulatory gastric pH monitoring: Validation of a new method and effect of H2-antagonists. Gastroenterology 1985; 88: 1842-51.

4 Savarino V, Mela GS, Scalabrini P, Sumberaz A, Fera G, Celle G. 24-hour study of intragastric acidity in duodenal ulcer patients and normal subjects using continuous intraluminal pH-metry. Dig Dis Sci 1988; 33: 1077-80.

should eliminate bacterial contamination before restarting. It may seem that a massive overdose of drug could be infused by this system if responses are poor. This could only occur if the programmed rates allowed it and if a massive reservoir of drug were available for infusion. The system flexibility ensures that it is possible to limit the total dose infused as well as the maximum infusion rate. If gastric secretion were stimulated (by food for example), the infusion rate would increase to the value required or to the highest value possible depending on intragastric $\mathrm{pH}$. It would not then infuse still higher doses unless it were reprogrammed. As the highest infusion rates programmed in this study were required in some subjects under basal (fasting) conditions it seems likely that much higher rates would need to be allowed if the system were to be expected to work during secretory stimulation.

The GastroJet system should be a powerful research tool in assessing the optimum dose of intravenous antisecretory agents used without the system. It can clearly show individual variations in response and may help to identify those
5 Andersen J, Naesdal J, Strom M. Identical 24-hour gastric pH profiles when using intragastric antimony or glass electrodes or aspirated gastric juice. Scand $\mathcal{F}$ Gastroenterol 1988; 23: 375-9.

6 Merki HS, Hunt RH, Walt RP, et al. A new programmable infusion pump for individual control of intragastric $\mathrm{pH}$ : Validation and effect of ranitidine. Eur $\mathcal{F}$ Gastroenterol (in press).

7 Vincek WC, Constanzer ML, Hessey GA, Bayne WF. Analytical method for the quantification of famotidine, an $\mathrm{H} 2$ receptor blocker, in plasma and urine. $\mathcal{F}$ Chromatogr 1985; 338: 438-43.

8 Sippy BW. Gastric and duodenal ulcer. Medical care by an efficient removal of gastric juice corrosion. $\mathcal{F} A M A 1915 ; 64$ : 1625-30.

9 Green FW, Kaplan MM, Curtis LE, Levine PH. Effect of acid and pepsin on blood coagulation and platelet aggregation: a possible contributor to prolonged gastroduodenal mucosal haemorrhage. Gastroenterology 1978; 74: 38-43.

10 Elashoff JD. Down with multiple T tests. Gastroenterology 1981; 80: 615-20.

11 Driks MR, Craven DE, Celli BR, et al. Nosocomial pneumonia in intubated patients given sucralfate as compared with antacids or histamine $\mathrm{H} 2$ blockers. The role of gastric colonisation. $N$ Engl f Med 1987; 317: 1376-82.

12 Du Moulin GC, Paterson DG, Hedley-Whyte J, Lisbon A Aspiration of gastric bacteria in antacid treated patients: a frequent cause of post-operative colonisation of the airway. Lancet 1982; i: $242-5$.

13 Atherton ST, White DJ. Stomach as source of bacteria colonising respiratory tract during artificial ventilation. colonising respiratory

14 Donowitz LG, Page MC, Mileur BL, Guenthner SH. Alteration of normal gastric flora in critical care patients receiving antacid and cimetidine therapy. Infect Control $1986 ; 7: 23-6$ 